\title{
Unmappable ventricular tachycardia after an old myocardial infarction. Long-term results of substrate modification in patients with an implantable cardioverter defibrillator
}

\author{
B. S. N. Alzand - C. C. M. M. Timmermans • \\ H. J. J. Wellens • R. Dennert • S. A. M. Philippens • \\ P. J. M. Portegijs • LM. Rodriguez
}

Received: 1 November 2010 / Accepted: 26 January 2011 /Published online: 22 February 2011

(C) The Author(s) 2011. This article is published with open access at Springerlink.com

\begin{abstract}
Purpose The frequent occurrence of ventricular tachycardia can create a serious problem in patients with an implantable cardioverter defibrillator. We assessed the long-term efficacy of catheter-based substrate modification using the voltage mapping technique of infarct-related ventricular tachycardia and recurrent device therapy.

Methods The study population consisted of 27 consecutive patients (age 68土8 years, 25 men, mean left ventricular ejection fraction $31 \pm 9 \%$ ) with an old myocardial infarction and multiple and/or hemodynamically not tolerated ventricular tachycardia necessitating repeated device therapy. A total of 31 substrate modification procedures were performed using the three-dimensional electroanatomical mapping system. Patients were followed up for a median of 23.5 (interquartile range 6.5-53.2) months before and 37.8 (interquartile range 11.7-71.8) months after ablation. Antiarrhythmic drugs were not changed after the procedure, and were stopped 6 to 9 months after the procedure in patients who did not show ventricular tachycardia recurrence.
\end{abstract}

"This article is dedicated to my supervisor Luz-Maria Rodriguez, who died June 21, 2009. She was extremely helpful, knowledgeable, and attentive. An exceptional teacher who I will always remember." Becker Alzand

B. S. N. Alzand · C. C. M. M. Timmermans · H. J. J. Wellens • R. Dennert • S. A. M. Philippens • P. J. M. Portegijs • LM. Rodriguez

Department of Cardiology, Cardiovascular Research Institute Maastricht, Maastricht University Medical Center,

Maastricht, The Netherlands

B. S. N. Alzand $(\bowtie)$

Department of Cardiology, Maastricht University Medical Center, P. Debyelaan 25, P.O. Box 5800, Maastricht, The Netherlands

e-mail: alzand@hotmail.com
Results Median ventricular tachycardias were 1.6 (interquartile range 0.7-6.7) per month before and 0.2 (interquartile range $0.00-1.3)$ per month after ablation $(P=$ 0.006). Nine ventricular fibrillation episodes were registered in seven patients before and two after ablation $(P=$ 0.025). Median antitachycardia pacing decreased from 1.6 (interquartile range 0.01-5.5) per month before to 0.18 (interquartile range $0.00-1.6)$ per month after ablation $(P=$ 0.069). Median number of shocks decreased from 0.19 (interquartile range $0.04-0.81$ ) per month before to 0.00 (interquartile range 0.00-0.09) per month after ablation $(P=$ 0.001). One patient had a transient ischemic attack during the procedure, and another developed pericarditis. Nine patients died during follow-up, eight patients due to heart failure and one patient during valve surgery.

Conclusion Catheter-based substrate modification using voltage mapping results in a long-lasting reduction of cardioverter defibrillator therapy in patients with multiple and/or hemodynamically not tolerated infarct-related ventricular tachyarrhythmia.

Keywords Ablation - Substrate modification . Tachyarrhythmia $\cdot$ Follow-up studies $\cdot$ Ventricular tachycardia

\section{Introduction}

Implantable cardioverter defibrillator (ICD) devices have improved prognosis in patients with low left ventricular ejection fraction (LVEF) and ventricular tachyarrhythmia. However, these devices are not capable of preventing recurrences of ventricular tachycardia (VT) appearing in up to $70 \%$ of patients. In $3 \%$ to $5 \%$ of patients, electrical 
storm occurs, often many years after infarction [1]. ICD shocks are painful, and repeated appropriate ICD shocks are an increasing clinical problem requiring hospital admission and are accompanied by anxiety and depression in more than $50 \%$ of patients [2-4]. ICD shocks require high voltage, and frequent shocks lead to premature depletion of the ICD battery and early device replacement. VT is the most common cause of appropriate ICD shocks. In the infarcted human heart, VTs usually arise in the subendocardial region using slowly conducting narrow bundles (smallest width $250 \mu \mathrm{m}$ ) of viable myocardium in and around the infarcted area [5-8]. Such a conducting channel differs from the surrounding scar tissue by a higher voltage [9]. As described by Arenal et al., a channel is called complete when it is surrounded by two scar areas, or one scar area and the mitral annulus and is connected to normal myocardium at least at two sites [10]. Incomplete channels are connected to normal myocardium at only one site [10]. The presence of multiple morphologies and/or hemodynamically intolerant VTs has limited the widespread applicability of conventional catheter ablation therapy [11, 12]. The voltage mapping approach during sinus rhythm is an effective approach to identify and ablate the slow conduction channels with an acute procedural success of about 75\% [13-15]. We report the long-term (median follow up of 3 years) results of our population who underwent this procedure.

\section{Methods}

\subsection{Study population}

From a group of 190 patients who underwent radiofrequency catheter ablation (RFCA) for VT at the academic hospital of Maastricht between November 2000 and December 2007, 86 patients had ischemic ventricular tachycardia. Our study population consisted of a subgroup of 27 consecutive patients who underwent substrate modification and RFCA using the voltage mapping technique and who had an ICD implanted. This strategy was prospectively decided because of unmappable VT(s). Although VT induction protocol was used in all patients at the beginning of each procedure, no mapping during VT was performed. Unmappable VT was defined as being hemodynamically unstable and/or having multiple clinical VT morphologies. Four of our patients had an incessant VT which changes morphologies. Incessant VT was defined as a VT that persists for more than half of a 24-h period. Seventeen patients had an electrical storm, defined as $\geq 3$ distinct arrhythmic episodes (VT/VF) in $24 \mathrm{~h}$ usually requiring electrical cardioversion or defibrillation [16]. The mean age of the patients was $68 \pm 8$ years, and all but two were men. The scar from the myocardial infarction was located: anterior in 12, inferior in 10, posterior in 3 , and inferoposterolateral in 2 patients. The mean time interval from infarction to catheter ablation was $21 \pm 8$ years. The mean LVEF was $31 \pm 9 \%$. Most patients were on a combination of amiodarone and a beta-blocker (19 patients). Six patients had only beta-blockers, one patient was on amiodarone alone, and one patient on sotalol alone (Table 1). VTs were documented by a 12-lead ECG. A sustained VT episode was clinically defined as a VT lasting more than $30 \mathrm{~s}$. All patients had an ICD during follow-up: 23 patients before the procedure (median 23.5 (interquartile range (IQR) 6.5-53.2) months) and 4 patients within a few days after the procedure. From the four patients in whom no ICD was implanted before the procedure, information of the VT episodes was obtained from the clinical chart, and thus underestimated. The ICD definition of sustained VT episode varies from 8 to 30 consecutive ventricular beats, depending on the ICD manufacturer and programming. AADs were not changed directly after the procedure. The beta-blockers and the sotalol were continued during the study (ischemic heart disease, concomitant paroxysmal atrial fibrillation). The amiodarone was stopped 6 to 9 months after the index procedure in the nine patients who did not had VT recurrences and 6 to 9 months after the second procedure in the two patients who did not had VT recurrences. AADs were not changed in the rest of the patients.

\subsection{Electrophysiological study, mapping, and ablation} technique

Patients were studied in a fasting state. During left ventricular (LV) mapping and ablation, heparin was administered to achieve and maintain an activated coagulation time $>250 \mathrm{~s}$, and the ICD was deactivated. Three $6 \mathrm{~F}$ quadripolar electrode catheters were advanced via the femoral vein to the high right atrium, His-bundle region, and right ventricular (RV) apex. All patients had a documented 12-lead ECG of the clinical VT(s). Patients underwent programmed electrical stimulation with up to three extrastimuli, using three different cycle lengths (600-500-430 ms). Pacing was performed only from the RV apex. All patients had at least one unmappable VT. Electroanatomical substrate mapping with the CARTO ${ }^{\text {TM }}$ system (Biosense-Webster Inc., Diamond Bar, CA) was performed using the retrograde aortic approach via the femoral artery during sinus rhythm (30 procedures) or RV pacing (1 procedure). Sequential point-by-point acquisition was done to build the LV geometry. Endocardial electrograms were analyzed and categorized according to the presence of late potentials and fragmented electrograms. Sites with an electrogram ampli- 
Table 1 Patient characteristics

\begin{tabular}{|c|c|c|c|c|c|c|c|c|c|c|}
\hline \multirow[t]{2}{*}{ Patient no. } & \multirow[t]{2}{*}{ Age } & \multirow[t]{2}{*}{ Sex } & \multirow[t]{2}{*}{ MI } & \multirow[t]{2}{*}{$\mathrm{EF} \%$} & \multirow{2}{*}{$\begin{array}{l}\text { Time from } \\
\text { MI (years) }\end{array}$} & \multirow[t]{2}{*}{ AAD } & \multicolumn{4}{|l|}{ Before ablation } \\
\hline & & & & & & & $\begin{array}{l}\text { No. of VT } \\
\text { episodes }\end{array}$ & $\begin{array}{l}\text { Morphology of } \\
\text { clinical VT(s) }\end{array}$ & $\begin{array}{l}\text { No. of } \\
\text { inducible VTs }\end{array}$ & $\begin{array}{l}\text { VT cycle length } \\
\text { range }(\mathrm{ms})\end{array}$ \\
\hline $1^{\mathrm{a}}$ & 76 & $\mathrm{~m}$ & I & 48 & 25 & Class III, BB & 15 & LB-LA(×2), RB-RA & 3 & $330-360$ \\
\hline $2^{\mathrm{a}}$ & 73 & $\mathrm{f}$ & $\mathrm{P}$ & 45 & 26 & Class III, BB & 15 & RB-LA, LB-LA $(\times 3)$ & 5 & $330-420$ \\
\hline 3 & 81 & $\mathrm{~m}$ & A & 26 & 37 & Class III, BB & Incessant (storm) & RB-NW, RB-LA & 2 & $320-400$ \\
\hline 4 & 71 & $\mathrm{~m}$ & I & 30 & 12 & Class III, BB & 82 (storm) & RB-LA, LB-IA & 2 & $300-310$ \\
\hline 5 & 69 & $\mathrm{~m}$ & I & 33 & 19 & Class III, BB & 87 (storm) & RB-LA & 1 & 270 \\
\hline $6^{\mathrm{a}}$ & 45 & $\mathrm{~m}$ & $\mathrm{~A}$ & 30 & 14 & Class III & 5 & RB-LA & 2 & $220-300$ \\
\hline 7 & 75 & $\mathrm{~m}$ & A & 25 & 17 & Class III, BB & 43 (storm) & RB-LA & 5 & $220-370$ \\
\hline 8 & 79 & $\mathrm{~m}$ & IPL & 35 & 16 & Class III, BB & 92 (storm) & RB-NW, LB-LA & 2 & $340-400$ \\
\hline 9 & 62 & $\mathrm{~m}$ & A & 36 & 21 & Class III, BB & 616 (storm) & LB-RA & 1 & 270 \\
\hline $10^{\mathrm{a}}$ & 70 & $\mathrm{~m}$ & I & 19 & 24 & Class III, BB & Incessant (storm) & RB-RA & 2 & $300-340$ \\
\hline 11 & 60 & $\mathrm{~m}$ & $\mathrm{P}$ & 38 & NA & Class III, BB & 132 (storm) & RB-LA & 1 & 300 \\
\hline 12 & 62 & $\mathrm{~m}$ & I & 30 & 17 & $\mathrm{BB}$ & 17 & RB-NW & 1 & 280 \\
\hline $13^{\mathrm{a}}$ & 54 & $\mathrm{~m}$ & A & 28 & 24 & Class III, BB & 170 (storm) & RB-NW & 5 & $330-480$ \\
\hline $14^{\mathrm{a}}$ & 58 & $\mathrm{~m}$ & A & 30 & 14 & Class III, BB & 15 & RB-LA & 2 & $320-370$ \\
\hline 15 & 77 & $\mathrm{~m}$ & A & 35 & 23 & Class III, BB & 10 & RB-LA(×2) & 2 & $330-340$ \\
\hline $16^{\mathrm{a}}$ & 60 & $\mathrm{~m}$ & A & 25 & 12 & $\mathrm{BB}$ & 20 & RB-NW, RB-RA & 2 & $320-470$ \\
\hline 17 & 67 & $\mathrm{~m}$ & $\mathrm{P}$ & 30 & 24 & Class III, BB & Incessant (storm) & RB-NW, RB-RA & 2 & $250-410$ \\
\hline 18 & 62 & $\mathrm{~m}$ & I & 50 & 24 & Class III & 15 & RB-RA, RB-LA & 2 & $480-520$ \\
\hline 19 & 70 & $\mathrm{~m}$ & A & 35 & 22 & $\mathrm{BB}$ & 58 (storm) & RB-RA $(\times 2)$ & 2 & $300-500$ \\
\hline 20 & 68 & $\mathrm{~m}$ & IPL & 20 & 19 & Class III, BB & Incessant (storm) & RB-NW, RB-RA & 2 & $250-600$ \\
\hline 21 & 73 & $\mathrm{f}$ & A & 25 & 40 & $\mathrm{BB}$ & 4 & RB-RA, RB-LA & 3 & $290-320$ \\
\hline $22^{\mathrm{a}}$ & 69 & $\mathrm{~m}$ & I & 45 & 7 & BB & 221 (storm) & RB-LA & 1 & 330 \\
\hline $23^{\mathrm{a}}$ & 74 & $\mathrm{~m}$ & $\mathrm{~A}$ & 24 & 30 & BB & 76 (storm) & RB-LA (×2) & 3 & $250-390$ \\
\hline 24 & 81 & $\mathrm{~m}$ & I & 20 & 28 & Class III, BB & 37 & LB-LA, RB-RA & 2 & $470-510$ \\
\hline 25 & 76 & $\mathrm{~m}$ & A & 22 & 11 & Class-III, BB & 2,979 (storm) & LB-LA\&RA,RB-RA & 3 & $360-550$ \\
\hline 26 & 75 & $\mathrm{~m}$ & I & 21 & 26 & Class-III, BB & 59 (storm) & RB-NW (×2) & 4 & $450-660$ \\
\hline 27 & 63 & $\mathrm{~m}$ & I & 30 & 20 & Class-III, BB & 51 (storm) & RB-LA, RB-NW & 5 & $250-230$ \\
\hline
\end{tabular}

$A$ anterior wall MI, $A A D$ antiarrhythmic drugs, $B B$ beta-blockers, Class-III class III antiarrhythmic drugs, $E F$ ejection fraction, $f$ female, $I$ inferior wall MI, $I A$ intermediate axis, IPL inferoposterolateral MI, $L A$ left axis, $L B$ left bundle branch block morphology, $M$ male, $M I$ myocardial infarction, $N W$ northwest axis, $R A$ right axis, $R B$ right bundle branch block morphology, storm, VT electrical storm, $V T$ ventricular tachycardia, $\times 2, \times 3$, indicates 2 or 3 different VT morphologies with the same bundle branch block and axis

${ }^{a}$ Patients in which irrigated tip catheter were used

tude $>1.5 \mathrm{mV}$ were considered normal myocardium, $<0.5 \mathrm{mV}$ as densely scarred endocardium [17], and values in between as the border zone of the infarction. Analysis of the voltage map, the clinical VT(s) morphology and the endocardial electrograms were performed to identify candidate regions of slow conduction responsible for the VT(s). Pace mapping was used to target the site of ablation in the majority of patients (Fig. 1). Ablation was performed using a conventional 4-mm tip RF ablation catheter (Cordis-Webster). If pace mapping produced 12lead QRS morphology similar to the targeted VT, a linear ablation lesion was made from the exit point parallel to the scar margin, from the exit point to the densely scarred myocardium or from a densely scarred myocardium to the mitral valve annulus (three patients). Reentry circuit isthmus was identified in five patients and was defined on the basis of the results of pace mapping as a site where the QRS morphology matched that of VT with a pacing stimulus-QRS interval of $\geq 40 \mathrm{~ms}$ [18, 19]. When the isthmus was identified, a linear lesion was made crossing the isthmus connecting two densely scarred areas. RF current was applied for $90 \mathrm{~s}$; temperature and power were limited to $60-70^{\circ} \mathrm{C}$ and $50 \mathrm{~W}$, respectively. Salineirrigated tip (SIT) catheter (The Thermo-Cool ${ }^{\mathrm{TM}}$ catheter, Cordis-Webster) was used seven times during the index procedure and two times during the second procedure. The 
(a)

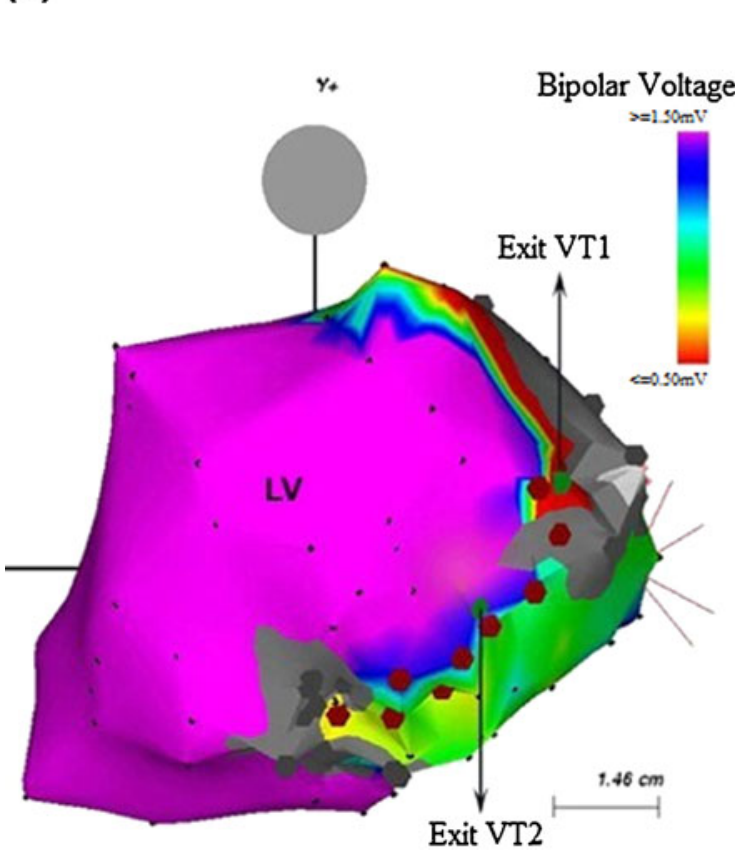

(b)

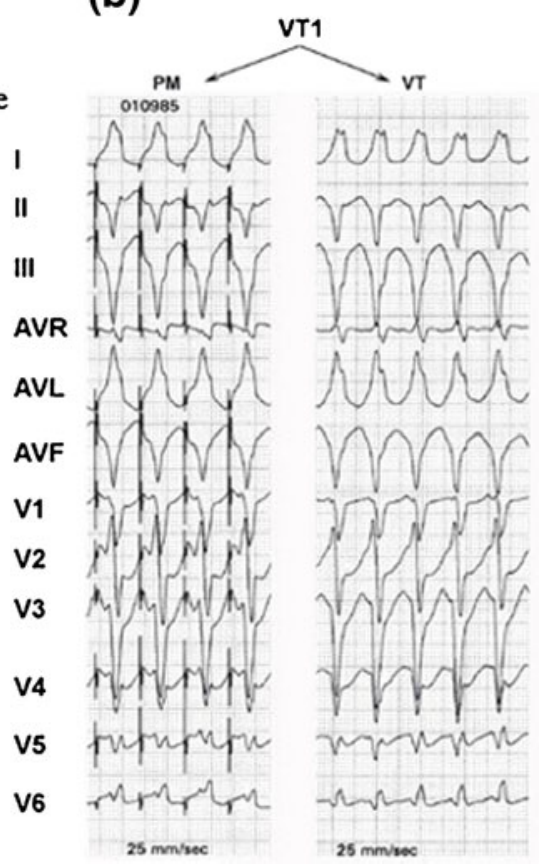

(c)

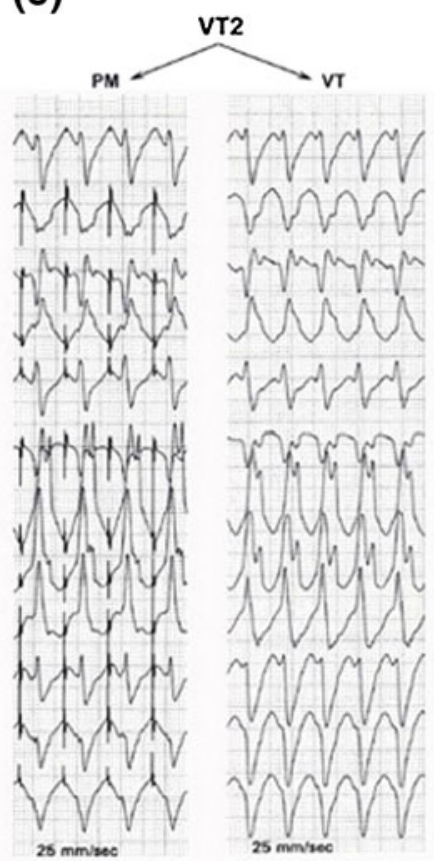

Fig. 1 (a) Voltage map during sinus rhythm of the left ventricle in a posterior-anterior view in a patient with an inferoposterolateral infarction. The patient had two different VTs: VT1 with left bundle branch block morphology and left axis, and VT2 with right bundle branch block morphology and northwest axis. Color range indicates the electrogram amplitude. Purple represents normal myocardium
$(>1.5 \mathrm{mV})$; gray, dense scar $(<0.5 \mathrm{mV})$; and range between purple and red, border zone $(0.5-1.5 \mathrm{mV})$. The 12-lead ECG during VT and pace mapping (b), (c) directed the linear ablation. Arrows indicate the site where the exit point of the VTs was found. Linear lesions (red dark dots) were extended from dense scar and across the border zone
SIT catheter was used in the power-controlled mode, with the target power set at $30 \mathrm{~W}$ and increased to $50 \mathrm{~W}$ when required. Temperature cutoff was programmed at $50^{\circ} \mathrm{C}$. RF pulse was delivered for $90 \mathrm{~s}$. Continuous saline flow was maintained at $2 \mathrm{~mL} / \mathrm{min}$ and increased to $30 \mathrm{~mL} / \mathrm{min}$ during RF delivery. Both clinical VT(s) and the preablation-induced VT(s) were targeted. Programmed stimulation with up to three extrastimuli using three different cycle lengths (600-500-430 ms) at one site (RV apex) was repeated to determine procedural success. Acute success was defined as the inability to reinduce both the clinical and the induced VT(s) before ablation.

\subsection{Follow-up}

Patients were followed up every 3 months in our ICD outpatient clinic. During these visits, the ICD was interrogated, and arrhythmic events and device therapy were analyzed. Interrogation intervals were shorter when clinically indicated. Not all VT episodes require therapy, and one VT episode may require more than one therapy, depending on the ICD programming. A 12-lead ECG was made in the cases in which the arrhythmia occurred inhospital, in all other cases recordings were obtained from the device memory.

\subsection{Statistical analysis}

Statistical analysis was performed using the SPSS software package version 15.0.0 (SPSS Inc, 2006). Variables are expressed as mean \pm standard deviation (SD) or median with interquartile range (IQR) when not normally distributed. Mean values were compared using the Student's $t$ test for paired data and median values using the Wilcoxon signed-rank test. Kaplan-Meier curve was used to calculate the cumulative probability of the remaining free from appropriate ICD shocks. Statistical significance was established at $P<0.05$.

\section{Results}

\subsection{Acute results}

A total of 67 different VTs were induced in the 27 patients studied during the index procedure $(2.5 \pm 1.3 \mathrm{VTs} /$ patient $)$. A single VT morphology was induced in five patients. In patients with an anterior wall myocardial infarction, the number of inducible VTs was $2.6 \pm 1.2$, and $1.3 \pm 0.7$ in patients with an inferior wall infarction $(P=0.03)$. The mean VT-cycle length (VTCL) was $363 \pm 101 \mathrm{~ms}$. There 
was no significant difference between the VTCL in patients with anterior $(345 \pm 85 \mathrm{~ms})$ versus inferior wall myocardial infarction $(365 \pm 112 \mathrm{~ms} ; P=0.13)$. The mean scar diameter was $66 \pm 22 \times 53 \pm 25 \mathrm{~mm}$ (area $40 \pm 24 \mathrm{~cm}^{2}$ ). The mean number of RF applications was $13 \pm 7$. All clinical and preablation inducible VTs were targeted and successfully ablated. There was no inducible VT after ablation in 21 patients. In the remaining six patients, eight VTs were induced (two patients had inducible polymorphic VT/VF and four patients had six inducible monomorphic VT(s) not matching the morphology or cycle length of the clinical or the preablation VT(s); these VT(s) were not targeted for ablation).

3.2 Duration of the procedure, fluoroscopy exposure, and complications

The mean procedure time was $290 \pm 92 \mathrm{~min}$, and the mean fluoroscopy time was $56 \pm 16 \mathrm{~min}$. One patient had a transient ischemic attack during the procedure, and another developed a self-limiting pericarditis.

\subsection{Long-term follow-up}

A total of $31 \mathrm{VT}$ ablation procedures were performed in 27 patients. After the index procedure, 23 patients $(85 \%)$ did not require a second ablation procedure. In four patients $(15 \%)$, a second procedure was necessary due to recurrence of multiple hemodynamically not tolerated VT(s) and repeated device therapies (three patients within 7 months and one patient after 4 years). Patients were followed up for a median of 23.5 (IQR 6.5-53.2) months before and 37.8 months (IQR 11.7-71.8) after the index procedure. Seven thousand seven hundred thirty-six episodes of VT were registered, 5,203 before and 2,533 after the procedure. Nine patients $(33 \%)$ remained completely free of VT after the index ablation (Fig. 2). The median number of VTs was
1.6 per month (IQR 0.7-6.7) before and 0.2 per month (IQR $0.00-1.3)$ after the index ablation, $(P=0.006)$. The mean recurrent VTCL was $531 \pm 98 \mathrm{~ms}$ which was longer than the VTCL $(363 \pm 101 \mathrm{~ms})$ before catheter ablation $(P=$ $0.0001)$. Nine VF episodes were registered in seven patients before and two after the index ablation $(P=0.025)$. A total of 9,251 antitachycardia pacing (ATP) episodes were registered during the study, 6,036 before and 3,212 after the procedure. Median ATP decreased from 1.6 (IQR 0.015.5 ) per month before to 0.18 (IQR $0.00-1.6$ ) per month after the index ablation $(P=0.069)$. Five hundred sixteen appropriate shocks were registered during the study, 409 before and 107 after the index ablation. Fourteen patients (52\%) remained free of ICD shocks after the index ablation (Fig. 3). Median number of shocks decreased from 0.19 per month (IQR 0.04-0.81) before to 0.00 per month (IQR $0.00-0.09)$ after the index ablation $(P=0.001)$. Of all patients, $63 \%(17 / 27)$ experienced at least $75 \%$ reduction in their monthly ICD interventions (ATP and shocks) after the index procedure. The probabilities of surviving free from any ICD shock after catheter ablation were $64 \%, 52 \%$, and $46 \%$ after 10,20 , and 50 months of follow-up, respectively (Fig. 4). The mean number of shocks was 7.2 per patient in the 3 months prior to catheter ablation, decreased to 0.7 shocks per patient in the 3 months after ablation and 0.2 shocks per patient per 3 months during the third year of follow-up. Irrigated tip catheter was used in seven patients during the index ablation procedure. Four of these patients remained free from any VT after the procedure (Figs. 2 and 3). From the 27 patients, four required a second catheter ablation procedure due to recurrence of hemodynamically not tolerated VTs and increased device therapy. Irrigated tip catheter was used in 2. After the second ablation, all four patients remained free of appropriate ICD shocks, and two of them remained free from VTs (Figs. 2 and 3). After the second procedure, 78\% of all patients $(21 / 27)$ had at least $75 \%$ reduction in their
Fig. 2 Diagram showing the total number of VTs and ATPs and the median follow-up period before and after substrate modification. Patients were divided according to VT recurrences. After the index procedure, nine patients were totally VT free. Four patients had recurrences requiring a second ablation procedure, and 14 patients had recurrences without the clinical necessity for a second ablation procedure. *ATP antitachycardia pacing, $F / U$ median follow-up period, $V T$ ventricular tachycardia

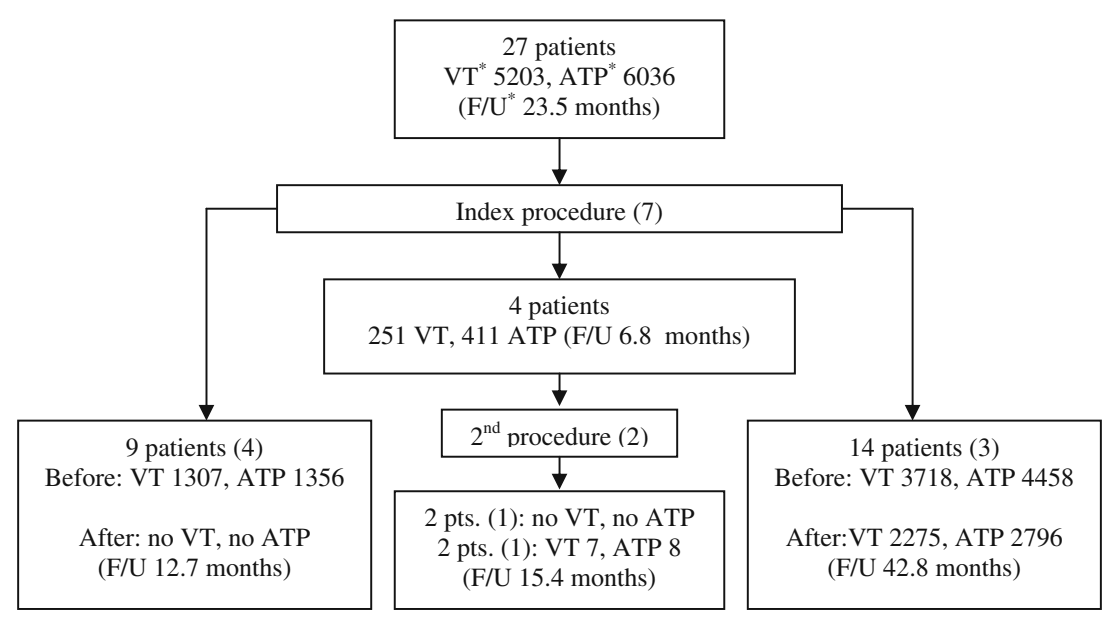


Fig. 3 Diagram showing the total number of appropriate ICD shocks and the median follow-up period before and after substrate modification. Patients are divided according to the occurrence of ICD shock. After the index procedure, 14 patients were totally shock free. Four patients had multiple shocks requiring a second ablation procedure, and nine patients had ICD shocks without the clinical necessity for a second ablation procedure. ${ }^{*} F / U$ median follow-up period

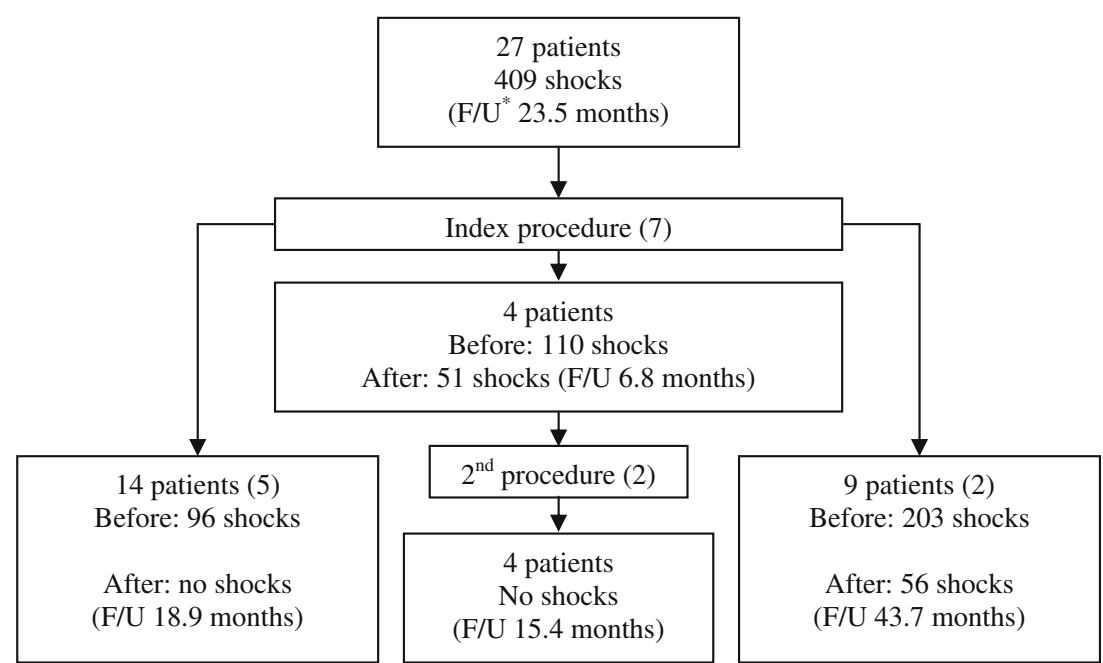

monthly ICD interventions (ATP and shocks). During the follow-up period, eight patients died due to heart failure and one patient during valve surgery.

\section{Discussion}

\subsection{Main findings}

To our knowledge, this is the first study reporting the longterm follow-up (37.8 months (IQR 11.7-71.8)) after substrate modification of unmappable VTs. In this study, the recurrence of VTs was continuously monitored with an ICD device. It reveals a significant long-lasting reduction of

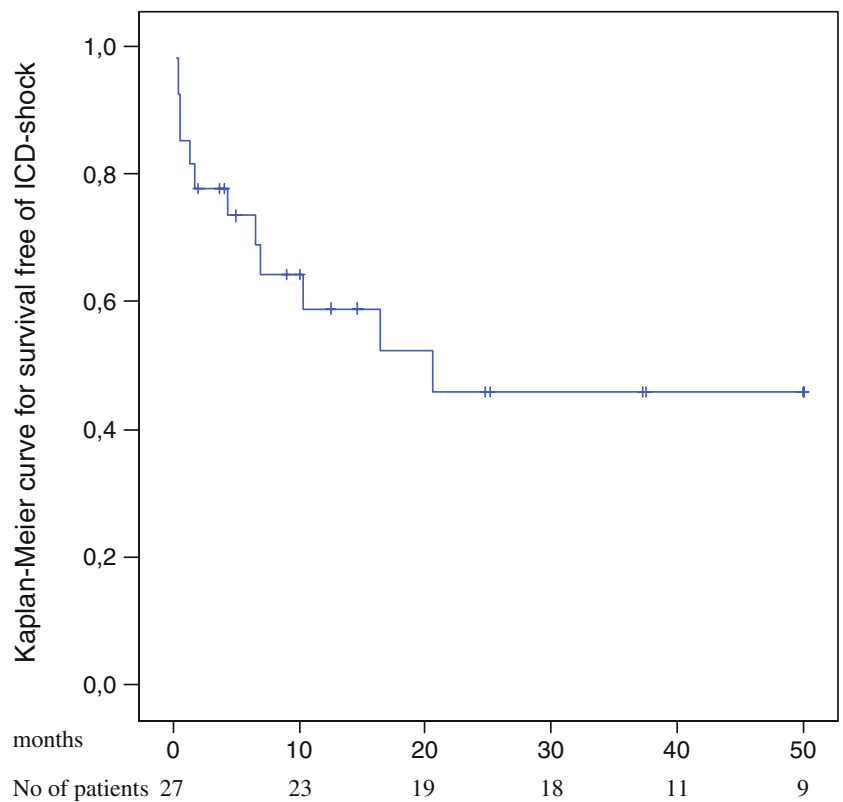

Fig. 4 Kaplan-Meier curve shows the probability of survival without an ICD shock till the 50th month of follow-up
VTs with a clinically relevant reduction of ICD therapy after substrate modification in patients who had suffered from frequent ICD shocks. Eighty-five percent of patients were clinically stable with no necessity for a second procedure. After an acute procedural success of $100 \%$, $33 \%$ of patients remained completely free from VT during follow-up. In case of VT recurrence, the VTs were significantly slower and less persistent. The number of ATPs per VT before $(6,036$ ATP to 5,203 $\mathrm{VT} \approx 1.2)$ is almost the same as after the index procedure (3,212 ATP to $2,533 \mathrm{VT} \approx 1.3)$. In the mean time, the number of $\mathrm{VT}$ episodes leading to one shock was clearly increased after ablation $(5,203 / 409 \approx 13$ versus $2,533 / 107 \approx 24)$. We believe that the prolongation in VTs' cycle length has made them better terminable with ATP contributing to a significant decrease in the number and the frequency of ICD shocks. Fifty-two percent and $67 \%$ of patients remained free from ICD shocks at the end of the study after the index and the second ablation procedure, respectively. Although irrigated tip catheters were only used in nine procedures, it seems that these catheters are more effective in preventing VT recurrence [20].

\subsection{Previous studies}

Long-term results of catheter ablation of unmappable VTs are unknown. Several studies have been published showing the short-term procedural results. When voltage mapping and ablation of the exit point — identified by pace mapping — were used, 46-93\% of patients remained free of VT after a followup of 3 to 8 months $[13,21,22]$. Voltage mapping and ablation of isthmuses identified by pace mapping (spike QRS $\geq 40 \mathrm{~ms}$ ) achieved 33-82\% survival free of VTs after 915 months of follow-up [15, 23, 24]. When using fractionated electrograms or electrograms with late potentials as guide for catheter ablation, $60-80 \%$ patients had no recurrent 
VT after a follow-up of 9-19 months [25-27]. However, some of these studies did not evaluate the arrhythmia occurrence using the continuous monitoring capability of the ICD $[15,24,27]$.

Our results cannot also be compared to the abovementioned studies because of the different methodology used in the identification of the origin of VTs, and because other VT etiologies were also included [13]. In some studies, not all patients were mapped during sinus rhythm $[15,21,23,27]$. However, when we analyzed only patients with an ICD and unmappable VTs due to an old myocardial infarction, one can see that the short-term results were almost comparable to our study despite having used a different methodology in modifying the substrate. It is important to emphasize that ICD interrogation helped to identify recurrence of VTs. Interestingly, the cycle length of the recurrent VTs was much longer than the one before the substrate modification, making them more responsive to ATP therapies.

\subsection{Clinical implications and future perspective}

This study, although not randomized, provides useful information regarding the management of patients with frequent ICD discharges. Catheter ablation reduced the frequency and persistency of VT, which is of clinical importance, because of the reduction of painful experiences, improvement in quality of life, and better long-term prognosis [28-31]. As shown in different studies [17, 30], the beneficial effect of catheter ablation in the patient with frequent ICD interventions is obvious, but an important question remains unanswered: Should every patient with VT(s), an old myocardial infarction, and an ICD undergo a substrate modification using the voltage mapping procedure? A large multicenter trial is needed to confirm whether catheter ablation improves the prognosis of patients with an old myocardial infarction, VT, and an ICD.

\subsection{Study limitations}

This study was a retrospective analysis and not a randomized trial. The study included a relatively small number of patients. The slow conduction zone(s) voltage mapping was done during sinus rhythm in almost all patients which is less sensitive in detecting late potentials and fragmented electrograms than voltage mapping during sinus rhythm combined with RV pacing or RV pacing alone as previously reported $[25,32]$. The central isthmus was only identified in five patients possibly due to the fact that we used a cutoff value of $<0.5 \mathrm{mV}$ to identify nonconducting scarred myocardium. Using a voltage map definition ranging from 0.5 to $0.2 \mathrm{mV}$ might have facilitated isthmus identification [10].

\section{Conclusion}

Catheter-based substrate modification using voltage mapping results in long-lasting reduction of VT and ICD discharges in patients with unmappable VT.

Disclosures The authors have read and approved the manuscript; they do not have conflicts of interest to disclose.

Open Access This article is distributed under the terms of the Creative Commons Attribution Noncommercial License which permits any noncommercial use, distribution, and reproduction in any medium, provided the original author(s) and source are credited.

\section{References}

1. Credner, S. C., Klingenheben, T., Mauss, O., Sticherling, C., \& Hohnloser, S. H. (1998). Electrical storm in patients with transvenous implantable cardioverter-defibrillators: incidence, management and prognostic implications. Journal of the American College of Cardiology, 32, 1909-1915.

2. Bilge, A. K., Ozben, B., Demircan, S., Cinar, M., Yilmaz, E., \& Adalet, K. (2006). Depression and anxiety status of patients with implantable cardioverter defibrillator and precipitating factors. Pacing and Clinical Electrophysiology, 29, 619-626.

3. Kamphuis, H. C., de Leeuw, J. R., Derksen, R., Hauer, R. N., \& Winnubst, J. A. (2003). Implantable cardioverter defibrillator recipients: quality of life in recipients with and without ICD shock delivery: a prospective study. Europace, 5, 381-389.

4. Sears, S. E., Jr., \& Conti, J. B. (2003). Understanding implantable cardioverter defibrillator shocks and storms: medical and psychosocial considerations for research and clinical care. Clinical Cardiology, 26, 107-111.

5. de Bakker, J. M., Coronel, R., Tasseron, S., Wilde, A. A., Opthof, T., Janse, M. J., et al. (1990). Ventricular tachycardia in the infarcted, Langendorff-perfused human heart: role of the arrangement of surviving cardiac fibers. Journal of the American College of Cardiology, 15, 1594-1607.

6. de Bakker, J. M., van Capelle, F. J., Janse, M. J., Tasseron, S., Vermeulen, J. T., de Jonge, N., et al. (1993). Slow conduction in the infarcted human heart. 'Zigzag' course of activation. Circulation, 88, 915-926.

7. de Bakker, J. M., van Capelle, F. J., Janse, M. J., Wilde, A. A., Coronel, R., Becker, A. E., et al. (1988). Reentry as a cause of ventricular tachycardia in patients with chronic ischemic heart disease: electrophysiologic and anatomic correlation. Circulation, 77, 589-606.

8. Rodriguez, L. M., \& Timmermans, C. (2005). Mechanical termination of ventricular tachycardia: conducting bundles bumped or blocked? Heart Rhythm, 2, 692-693.

9. Callans, D. J., Ren, J. F., Michele, J., Marchlinski, F. E., \& Dillon, S. M. (1999). Electroanatomic left ventricular mapping in the porcine model of healed anterior myocardial infarction. Correlation with intracardiac echocardiography and pathological analysis. Circulation, 100, 1744-1750.

10. Arenal, A., del Castillo, S., Gonzalez-Torrecilla, E., Atienza, F., Ortiz, M., Jimenez, J., et al. (2004). Tachycardia-related channel in the scar tissue in patients with sustained monomorphic ventricular tachycardias: influence of the voltage scar definition. Circulation, 110, 2568-2574. 
11. Morady, F., Harvey, M., Kalbfleisch, S. J., el-Atassi, R., Calkins, H., \& Langberg, J. J. (1993). Radiofrequency catheter ablation of ventricular tachycardia in patients with coronary artery disease. Circulation, 87, 363-372.

12. Stevenson, W. G., Khan, H., Sager, P., Saxon, L. A., Middlekauff, H. R., Natterson, P. D., et al. (1993). Identification of reentry circuit sites during catheter mapping and radiofrequency ablation of ventricular tachycardia late after myocardial infarction. Circulation, 88, 1647-1670.

13. Marchlinski, F. E., Callans, D. J., Gottlieb, C. D., \& Zado, E. (2000). Linear ablation lesions for control of unmappable ventricular tachycardia in patients with ischemic and nonischemic cardiomyopathy. Circulation, 101, 1288-1296.

14. Stevenson, W. G., Friedman, P. L., Kocovic, D., Sager, P. T., Saxon, L. A., \& Pavri, B. (1998). Radiofrequency catheter ablation of ventricular tachycardia after myocardial infarction. Circulation, 98, 308-314.

15. Soejima, K., Suzuki, M., Maisel, W. H., Brunckhorst, C. B., Delacretaz, E., Blier, L., et al. (2001). Catheter ablation in patients with multiple and unstable ventricular tachycardias after myocardial infarction: short ablation lines guided by reentry circuit isthmuses and sinus rhythm mapping. Circulation, 104, 664-669.

16. Dorian, P., \& Cass, D. (1997). An overview of the management of electrical storm. The Canadian Journal of Cardiology, 13(Suppl A), $13 \mathrm{~A}-17 \mathrm{~A}$.

17. Ellison, K. E., Stevenson, W. G., Sweeney, M. O., et al. (2000). Catheter ablation for hemodynamically unstable monomorphic ventricular tachycardia. Journal of Cardiovascular Electrophysiology, 11, 41-44.

18. Stevenson, W. G., Sager, P. T., Natterson, P. D., et al. (1995). Relation of pace mapping QRS and conduction delay to ventricular tachycardia reentry circuits in human infarct scars. Journal of the American College of Cardiology, 26, 481-488.

19. Stevenson, W. G., Friedman, P. L., \& Ganz, L. I. (1997). Radiofrequency catheter ablation of ventricular tachycardia late after myocardial infarction. Journal of Cardiovascular Electrophysiology, 8, 1309-1319.

20. Nabar, A., Rodriguez, L. M., Timmermans, C., \& Wellens, H. J. (2001). Use of a saline-irrigated tip catheter for ablation of ventricular tachycardia resistant to conventional radiofrequency ablation: early experience. Journal of Cardiovascular Electrophysiology, 12(2), 153-161.

21. Sra, J., Bhatia, A., Dhala, A., Blanck, Z., Deshpande, S., Cooley, R., et al. (2001). Electroanatomically guided catheter ablation of ventricular tachycardias causing multiple defibrillator shocks. Pacing and Clinical Electrophysiology, 24, 1645-1652.

22. Deneke, T., Grewe, P. H., Lawo, T., Calcum, B., Mugge, A., \& Lemke, B. (2005). Substrate-modification using electroanatomical mapping in sinus rhythm to treat ventricular tachycardia in patients with ischemic cardiomyopathy. Zeitschrift für Kardiologie, 94, 453-460.

23. Kottkamp, H., Wetzel, U., Schirdewahn, P., Dorszewski, A., Gerds-Li, J. H., Carbucicchio, C., et al. (2003). Catheter ablation of ventricular tachycardia in remote myocardial infarction: substrate description guiding placement of individual linear lesions targeting noninducibility. Journal of Cardiovascular Electrophysiology, 14, 675-681.

24. Reddy, V. Y., Neuzil, P., Taborsky, M., \& Ruskin, J. N. (2003). Short-term results of substrate mapping and radiofrequency ablation of ischemic ventricular tachycardia using a salineirrigated catheter. Journal of the American College of Cardiology, 41, 2228-2236.

25. Arenal, A., Glez-Torrecilla, E., Ortiz, M., Villacastin, J., FdezPortales, J., Sousa, E., et al. (2003). Ablation of electrograms with an isolated, delayed component as treatment of unmappable monomorphic ventricular tachycardias in patients with structural heart disease. Journal of the American College of Cardiology, 41, 81-92.

26. Schreieck, J., Zrenner, B., Deisenhofer, I., \& Schmitt, C. (2005). Rescue ablation of electrical storm in patients with ischemic cardiomyopathy: a potential-guided ablation approach by modifying substrate of intractable, unmappable ventricular tachycardias. Heart Rhythm, 2, 10-14.

27. Kautzner, J., Cihak, R., Peichl, P., Vancura, V., \& Bytesnik, J. (2003). Catheter ablation of ventricular tachycardia following myocardial infarction using three-dimensional electroanatomical mapping. Pacing and Clinical Electrophysiology, 26, 342-347.

28. Hohnloser, S. H., Kuck, K. H., Dorian, P., Roberts, R. S., Hampton, J. R., Hatala, R., et al. (2004). Prophylactic use of an implantable cardioverter-defibrillator after acute myocardial infarction. The New England Journal of Medicine, 351, 2481-2488.

29. Moss, A. J., Greenberg, H., Case, R. B., Zareba, W., Hall, W. J., Brown, M. W., et al. (2004). Long-term clinical course of patients after termination of ventricular tachyarrhythmia by an implanted defibrillator. Circulation, 110, 3760-3765.

30. Reddy, V. Y., Reynolds, M. R., Neuzil, P., Richardson, A. W., Taborsky, M., Jongnarangsin, K., et al. (2007). Prophylactic catheter ablation for the prevention of defibrillator therapy. The New England Journal of Medicine, 357, 2657-2665.

31. Sauer, W. H., Zado, E., Gerstenfeld, E. P., Marchlinski, F. E., \& Callans, D. J. (2010). Incidence and predictors of mortality following ablation of ventricular tachycardia in patients with an implantable cardioverter-defibrillator. Heart Rhythm, 7(1), 9-14.

32. Brunckhorst, C. B., Stevenson, W. G., Jackman, W. M., Kuck, K. H., Soejima, K., Nakagawa, H., et al. (2002). Ventricular mapping during atrial and ventricular pacing. Relationship of multipotential electrograms to ventricular tachycardia reentry circuits after myocardial infarction. European Heart Journal, 23, 1131-1138. 